\title{
DISTORÇÃO IDADE-SÉRIE EM MEIO ÀS POLÍTICAS EDUCACIONAIS NEOLIBERAIS
}

\author{
Age-Grade Distortion among neoliberal educational policies
}

\author{
Distorción Edad-Grado entre políticas educativas neoliberales
}

Valéria Prazeres dos Santos*

Arlete Ramos dos Santos ${ }^{* *}$

\begin{abstract}
Resumo
O presente texto objetiva discutir o problema da Distorção Idade-Série no Brasil, contextualizando-o historicamente, mas focando no momento atual em que a resolução do problema se alinha com os interesses neoliberais para a educação que inclui cada vez mais o empresariamento da educação. A abordagem teórica acolhida é a que possibilita uma postura crítica com um olhar materialista histórico-dialético da realidade social, pois para compreender os fenômenos sociais é preciso compreender a realidade como resultado de um processo histórico, dialético, vivo e que precisa ser superado para fins de desalienação e emancipação humana.
\end{abstract}

PALAVRAS-CHAVE: Distorção Idade-Série. Neoliberalismo. Políticas Educacionais.

\begin{abstract}
This text aims to discuss the problem of Age-Grade Distortion in Brazil, contextualizing it historically, but focusing on the current moment in which the resolution of the problem aligns with the neoliberal interests for education that increasingly includes the process of entrepreneurship in education. The accepted theoretical approach is one that enables a critical posture with a materialistic historical-dialectical view of social reality, because to understand social phenomena it is necessary to understand reality as a result of a historical, dialectical, living process that needs to be overcome for purposes of disalienation and human emancipation.
\end{abstract}

KEYWORDS: Age-Series Distortion. Neoliberalism. Educational Policies.

\footnotetext{
* Mestra em Educação pela Universidade Estadual de Santa Cruz (UESC). Coordenadora Pedagógica pela Rede Estadual da Bahia. Integrante do Grupo de Estudos Movimentos Sociais, Diversidade e Educação do Campo (GEPEMDECC/CNPq). E-mail: prof.valeriah@gmail.com Orcid: https://orcid.org/00000003-1155-1839

${ }^{* *}$ Pós-doutorado em Educação e Movimentos sociais na UNESP. Doutora em Educação pela Universidade Federal de Minas Gerais (UFMG). Professora Titular da Universidade Estadual do Sudoeste da Bahia (UESB). Docente do Programa de Pós-Graduação em Educação da UESC. Docente do Programa de Pós-Graduação em Educação da UESB. Coordenação Grupo de Estudos Movimentos Sociais, Diversidade e Educação do Campo (GEPEMDECC/CNPq). E-mail: arlerp@ hotmail.com Orcid: https://orcid.org/0000-0003-0217-3805
} 


\section{Resumen}

Este texto tiene como objetivo discutir el problema de la Distorsión Grado-Edad en Brasil, contextualizándolo históricamente, pero enfocándose en el momento actual en que la resolución del problema se alinea con los intereses neoliberales para la educación que incluye cada vez más el espíritu empresarial de la educación. El enfoque teórico aceptado es uno que permite una postura crítica con una visión materialista histórico-dialéctica de la realidad social, porque para comprender los fenómenos sociales es necesario comprender la realidad como resultado de un proceso histórico, dialéctico y viviente que necesita ser superado para propósitos de desalienación y emancipación humana.

PALABRAS CLAVE: Distorsión de series de edad. Neoliberalismo Políticas educativas.

\section{INTRODUÇÃO}

\section{"Gente é pra brilhar, não pra morrer de fome"}

O trecho da música Gente, de Caetano Caetano Veloso, compositor e cantor brasileiro/baiano, nos traz algo que é tão simples e caro, que abraça a teoria marxista e toda a luta da militância: ser gente é mais do que viver para produzir, é mais do que ter apenas o necessário para viver e produzir mais para quem vive dos excedentes, da exploração, da mais-valia. Portanto, discutir e buscar alternativas para a justiça social, inclusão e democracia é mais do que importante, é urgente e necessário. Para Marx (2014, p.102) O mais-valor, ou mais-valia, resulta, pois, da transformação do valor de uma mercadoria que vem a ser pago depois que seu valor de uso, sob o comando do capital, recria o antigo valor de troca como uma substância capaz de aumentar por si mesma.

A crise quando se expande, explicita as mazelas do capitalismo e expõe a crueldade do sistema, mas as precariedades imputadas à vida da maioria da população estão sempre

presentes, porque são estruturais, e a transformação tem que ser feita para modificar a estrutura; algo que, óbvio, não nasce nas reformas feitas pelos Estado, nem pelas empresas, tal como advogam as premissas neoliberais e os seus reformismos (MÉSZÁROS, 2011).

Entretanto, vivemos no Estado capitalista através do qual seguimos buscando caminhos que vão contra a sua natureza, por meio dele que fazemos correlação de forças, em todas as áreas (educação, moradia, emprego, segurança, políticas setoriais, entre outros), sendo necessário reestabelecer um constante trabalho de mobilização a partir da práxis materialista de associação conjunta entre teoria e prática e, assim, traçarmos alternativas. Para Mészáros (2011, p.27), a mudança vem de uma "transformação que deve ser feita por meio da adoção de práticas responsáveis e racionais necessárias para a única economia viável, orientada pela necessidade humana, ao invés do alienante, desumanizante e degradante lucro."

Buscando debater a partir dessa perspectiva contrária ao capital e o seu empresariamento na educação, discutiremos neste texto, a questão da Distorção Idade-Série (DIS), que é colocada nesse lugar de social e de necessária transformação. A DIS é um problema que alcança milhares de crianças e adolescentes na Educação Básica, predominantemente de escolas públicas. A temática parte de um recorte da dissertação de 
Mestrado nomeada $A$ distorção idade-série nas escolas do campo: um estudo sobre os Anos Iniciais do Ensino Fundamental no Município de Nazaré-BA. Para este texto, pretendemos problematizar a DIS, partindo de uma análise histórica do problema e o lugar do mesmo na educação do país, obviamente, compreendemos que pela limitação do texto não conseguiremos abranger todas as determinações que abraçam o fenômeno em âmbito nacional.

\section{Distorção Idade-Série no Brasil}

De acordo com Santos (2019), Distorção Idade-Série ou defasagem idade-série é a condição em que se encontram alunos cuja idade destoa da série/ano na qual os mesmos deveriam estar. No Brasil, a Constituição Federal de 1988 assegura em seu artigo 208 que o Estado deve ofertar educação básica obrigatória e gratuita dos 4 (quatro) aos 17 (dezessete) anos de idade, assegurada inclusive sua oferta gratuita para todos os que a ela não tiveram acesso na idade própria.

A Educação Básica é dividida em pré-escola, ensino fundamental e ensino médio. A primeira etapa não tem o objetivo de promoção, conforme assegura o artigo 31 da LDB (9.394/96). Aos seis anos, o aluno ingressa no Ensino Fundamental e deve concluí-lo, caso não tenha impedimento; aos catorze anos de idade, prosseguindo para o Ensino Médio de, no mínimo 3 anos, completando o ciclo da Educação Básica aos 17 anos.

O Ministério da Educação (MEC) entende que está em distorção/defasagem o aluno que se encontra em 2 anos ou mais de "atraso" em relação ao ano que deveria estar cursando. A distorção está associada às reprovações seguidas, mas também ao abandono e à entrada tardia dos alunos no ensino fundamental. Pode-se afirmar que o problema adquire mais evidência com a democratização do ensino a partir do momento em que a escola deixa de ser um lugar explicitamente para "selecionados" e passa a ser aparentemente "para todos"; e por isso, a reprovação, a evasão e a desistência passam a permear esse espaço.

A afirmação pode ser observada através da análise dos dados de Distorção Idade-Série no Brasil entre escolas públicas e privadas na Educação Básica. Segundo dados do Censo Escolar, do ano de 2018, a DIS encontra-se nos seguintes índices apresentados no quadro 1:

Quadro 1 - Distorção Idade-Série no Brasil - Escolas Públicas x Escolas Privadas

\begin{tabular}{|l|l|l|}
\hline & Públicas & Privadas \\
\hline Anos Iniciais & $14 \%$ & $4 \%$ \\
\hline Anos Finais & $29 \%$ & $7 \%$ \\
\hline Ensino Médio & $31 \%$ & $7 \%$ \\
\hline
\end{tabular}

Fonte: Censo escolar (2019). Nota: Elaboração própria.

O quadro 01 mostra que há uma disparidade no índice de alunos em DIS entre escolas públicas e privadas do país, sendo que a cada etapa essa disparidade se acentua, aumentando a diferença. Com isso, não estamos dizendo que a reprovação não acontece na escola privada e com os mais ricos, mas que ela acontece, com eles, de forma diferenciada. Todavia, os dados de Distorção Idade-Série entre escolas públicas e privadas, bem como o destaque para o fato de que os seus índices são mais altos em estados e regiões com menor renda per capita ${ }^{l}$ destaca o viés de classe, às quais as discussões são, aqui, focalizadas, de que há um hiato

\footnotetext{
${ }^{1}$ Abordagem ampliada na dissertação de Santos (2019).
} 
entre as condições de sucesso escolar que estão submetidos os alunos da escola pública. Apresentamos no quadro 2, a distribuição dos índices de DIS entre os estados do Brasil, demonstrando as médias das escolas públicas e privadas de cada estado da federação em três etapas da Educação Básica para o ano de 2017.

\begin{tabular}{|l|c|c|c|}
\multicolumn{4}{c}{ Quadro 2 - Distorção Idade-Série por etapa de ensino no ano de 2017 } \\
\hline & $\begin{array}{c}\text { ANOS INICIAIS DO } \\
\text { ENSINO } \\
\text { FUNDAMENTAL }\end{array}$ & $\begin{array}{c}\text { ANOS FINAIS DO } \\
\text { ENSINO } \\
\text { FUNDAMENTAL }\end{array}$ & ENSINO MÉDIO \\
\hline Rondônia & $12 \%$ & $32 \%$ & $31 \%$ \\
\hline Acre & $22 \%$ & $30 \%$ & $29 \%$ \\
\hline Amazonas & $18 \%$ & $33 \%$ & $42 \%$ \\
\hline Roraima & $14 \%$ & $28 \%$ & $28 \%$ \\
\hline Pará & $23 \%$ & $41 \%$ & $47 \%$ \\
\hline Amapá & $22 \%$ & $35 \%$ & $35 \%$ \\
\hline Tocantins & $10 \%$ & $28 \%$ & $30 \%$ \\
\hline Maranhão & $15 \%$ & $33 \%$ & $37 \%$ \\
\hline Piauí & $20 \%$ & $35 \%$ & $39 \%$ \\
\hline Ceará & $9 \%$ & $22 \%$ & $28 \%$ \\
\hline Rio Grande do Norte & $15 \%$ & $38 \%$ & $43 \%$ \\
\hline Paraíba & $17 \%$ & $36 \%$ & $35 \%$ \\
\hline Pernambuco & $17 \%$ & $30 \%$ & $27 \%$ \\
\hline Alagoas & $20 \%$ & $38 \%$ & $36 \%$ \\
\hline Sergipe & $21 \%$ & $43 \%$ & $43 \%$ \\
\hline Bahia & $21 \%$ & $41 \%$ & $44 \%$ \\
\hline Minas Gerais & $4 \%$ & $20 \%$ & $27 \%$ \\
\hline Espírito Santo & $13 \%$ & $30 \%$ & $26 \%$ \\
\hline Rio de Janeiro & $18 \%$ & $31 \%$ & $34 \%$ \\
\hline São Paulo & $5 \%$ & $11 \%$ & $13 \%$ \\
\hline Paraná & $6 \%$ & $18 \%$ & $23 \%$ \\
\hline Santa Catarina & $7 \%$ & $21 \%$ & $23 \%$ \\
\hline Rio Grande do Sul & $12 \%$ & $31 \%$ & $33 \%$ \\
\hline Mato Grosso do Sul & $16 \%$ & $32 \%$ & $35 \%$ \\
\hline Mato Grosso & $5 \%$ & $10 \%$ & $26 \%$ \\
\hline Goiás & $9 \%$ & $21 \%$ & $23 \%$ \\
\hline Fore: Censo & & \\
\hline
\end{tabular}

Fonte: Censo escolar (2018). Elaboração própria

O quadro 2 pode ser campo de diversas análises, mas focaremos aqui em duas, a primeira é a de que a DIS é progressiva entre as etapas, e a segunda a de que os estados do Norte $(\mathrm{N}) /$ Nordeste(NE) se destacam nos índices elevados desde a etapa de Anos Iniciais, como é o caso da Bahia e de Sergipe (NE), do Acre, Pará e Amapá (N).

Existem as diversas formas de exclusão dentro do próprio sistema escolar, essa exclusão se explicita em condições de acesso às escolas, deslocamento (aqui é necessário destacar o fechamento das escolas do campo e da cidade, mas sobretudo da primeira), formação docente inicial, formação continuada, infraestrutura das escolas públicas, concepção de avaliação (perpassa escolas públicas e privadas que se apoiam numa concepção classificatória de avaliação ${ }^{2}$ ), além de questões estruturais familiares e de quanto essas

\footnotetext{
${ }^{2}$ Ver mais em Freitas $(1995 ; 2014)$
} 
questões servem à manutenção do status quo, tal como Freitas $(1995 ; 2014)$, que em um estudo $^{3}$ analisa que a avaliação funcionava como uma âncora para as atuais funções sociais da escola, em especial para sua função de subordinação do estudante. Mais recentemente, este autor volta a fazer a mesma crítica acrescentando que com as avaliações externas tal fato aprofundou-se. Para Freitas (2014, p.1089),

É esta centralidade da avaliação escolar (fortalecida agora pela associação com a avaliação externa e as políticas de responsabilização) que é disputada e usada hoje pelos reformadores empresariais da educação para impor uma trava a possíveis avanços progressistas na organização do trabalho pedagógico da sala de aula e da escola - seja em seus objetivos, seja em sua avaliação - fortalecendo seu controle ideológico sobre toda a estrutura educacional que forma milhões de jovens, ajustando-os a um padrão cultural "básico" de instrução (ARROYO, 2009).

Para discutir como o problema é diferente no ensino privado, Mandelert (2010), em um artigo, recorte de sua tese de doutorado, faz um estudo de caso de duas escolas privadas, consideradas de prestígio do Rio de Janeiro, ambas com alto índice de aprovação no Exame Nacional do Ensino Médio (ENEM). No texto, a autora realiza um mapeamento sobre quando essas escolas reprovam, quantos alunos são reprovados, o que acontece com esses alunos e, finalmente, como as escolas recompõem as turmas com as sucessivas reprovações que ocorrem durante uma geração escolar.

Os estudos de Mandelert (2010) apontaram, sobretudo, o movimento de seletividade pelos quais os alunos que não se adaptam à escola passam, sendo, frequentemente, transferidos para outras, inclusive porque, segundo a autora, as próprias escolas não estimulam a permanência dos repetentes - o que pode justificar, em parte, os índices apresentados no quadro 1 .

A autora ressalta a forte seletividade das escolas privadas, que se dá, inclusive, desde o valor das mensalidades, às provas de nivelamento feitas para novos ingressantes. Entretanto, faz um adendo no que tange às escolas privadas e públicas: a de que ambas são para poucos, sendo que a seletividade se torna tanto para as escolas privadas, quanto para as públicas uma marca de "qualidade", em que só os "melhores" vão adiante, não importam as questões subjetivas inerentes a todos os sujeitos, nem a subjetividade do conceito de qualidade presentes nessas escolas.

Essa constatação discutida por Mandelert é difícil de ser digerida, mas é exatamente uma premissa neoliberal meritocrática e excludente. Os repetentes são empurrados das escolas particulares; nas escolas públicas os alunos reprovados enfrentam dificuldades de ressocialização e recuperação/construção do saber escolar, são muitas vezes estigmatizados, ficam à margem e muitos abandonam os estudos (SANTOS, 2019). Mas, talvez, mais grave do que tudo isso, seja o fato principal de que se não aprovou é porque não aprendeu aquilo que é considerado suficiente, ou ainda, se não aprendeu, é porque a escola não cumpriu o seu papel principal de tornar possível a aprendizagem. E isso não pode ser ignorado. A esse respeito é importante a discussão de Alves; Melo Júnior e Caiado (2018, p.192) ao apontarem que

\footnotetext{
${ }^{3}$ Estudo compilado no livro Crítica da Organização do Trabalho Pedagógico e da Didática, 1995.
} 
[...] a educação escolar básica brasileira tem sido objeto de contradições entre aquilo que se considera fundamental para o processo de transformação e emancipação social, e sua efetivação prática, haja vista os antagonismos que sempre permearam os interesses hegemônicos que fundamentam a atuação do Estado brasileiro na elaboração de Políticas e dos programas educacionais (BEZERRA NETO; BEZERRA; CAIADO, 2011).

Freitas (2014, p.1089) assinala o dilema vivenciado pelo capital de "como liberar um pouco mais de conhecimento para as camadas populares sem abrir mão do controle ideológico da escola, sem correr o risco de eventualmente abrir espaço para as teorias pedagógicas mais progressistas, comprometidas com as transformações da escola [...]?”. Assim, salientamos que deve estar claro para todos a questão de que a escola se molda, em detrimento do que é exigido pelo mercado.

Também não pode ser ignorado o fato de que é preciso um olhar histórico e de totalidade para o problema da DIS nas escolas públicas. Sim, porque o próprio método materialista histórico-dialético sob o qual propusemos a analisar a realidade nos diz que os fenômenos não surgem do acaso, nem mostram de imediato a sua verdadeira essência (KOSIK, 1976). Para o método um fenômeno se constitui de contradições, movimentos e transformações que em suas relações e inter-relações se articulam na totalidade, sendo essa a síntese de muitas determinações.

Segundo o dicionário de Filosofia (1997, p. 358), o termo essência pode ser definido por aquilo que responde à pergunta: o quê? Compreende a natureza de um ser, de uma coisa. Consiste na revelação daquilo que não se dá a conhecer de imediato. Já o termo aparência (1997, p. 68) tem dois significados opostos. Sendo que o primeiro é a ocultação da realidade, que parece real, vela ou obscurece a realidade das coisas, de tal modo que essa só pode ser reconhecida quando se transpõe a aparência e se abstrai dela.

Julgar as escolas públicas como lócus de reprovação e somando a elas todos os outros problemas por nós já conhecidos como condições de infraestrutura, deficiência de recursos físicos e didáticos entre outros fatores, sem compreender que a própria degradação/inferiorização faz parte de um contexto de destruição do público em detrimento do privado, compõem a essência do neoliberalismo.

A máxima neoliberal de diminuição do Estado nas demandas sociais está pujante e demarca fortemente a diferença entre ricos e pobres. Hipólyto e Lima (2019) chamam atenção para a organização da chamada Nova Direita que consistiria numa aliança entre conservadores e neoliberais agindo conjuntamente para o desmantelamento do Estado de Bem-Estar ${ }^{4}$ e para a criação de uma nova forma de administrar o Estado a partir da crise de 1970, período em que essa aliança começou a se consolidar.

Esta política atualmente aplicada visa também aprofundar o programa educacional neoliberal instalado no contexto brasileiro desde a década de 1990, submetendo o ensino público à lógica do empresariado e da privatização, desresponsabilizando o Estado do compromisso político-econômico de financiamento educacional. Nesse sentido, ocorre a transferência do eixo do processo formativo para a responsabilização individual da aprendizagem, sob a falácia do espírito empreendedor e das autoaprendizagens, muitas destas escondidas em nomenclaturas resinificadas pela própria política neoliberal como

\footnotetext{
${ }^{4}$ De acordo com Groppo (2005), o chamado Estado de Bem-Estar (Welfare State) pode ser conceituado como uma das formas de estado capitalista que é mais aberto às demandas sociais de modo que suaviza os conflitos de classe, tendo seus limites de aplicabilidade nos movimentos do Estado capitalista.
} 
Protagonismo Juvenil, autonomia, entre outros ${ }^{5}$. A esse respeito destacamos a fala de Marsiglia et al (2017, p. 112), ao apontar que

\begin{abstract}
Historicamente, a classe empresarial tem atuado para subordinar a escola pública às concepções que visam distanciar o conhecimento das necessidades humanas reais, sugerindo que o domínio amplo do saber sistematizado seria supérfluo à classe trabalhadora em função de suas necessidades imediatas de vida. Com efeito, a política educacional no Brasil tem reiterado a tendência de apropriação privada das formas mais desenvolvidas dos conhecimentos científicos, filosóficos e artísticos produzidos pela humanidade, o que se observa, inclusive, no âmbito das reformas curriculares.
\end{abstract}

Essas instituições privadas vêm produzindo materiais para retratar os índices da educação pública e basear as reformas nessas evidências numéricas. Freitas, a esse respeito colabora:

[...]a questão é a produção de 'política com evidência', ao centrar-se na organização e análise dos números, oculta as concepções que jazem a estes e impede uma discussão sobre a concepção de educação e de sociedade que deve orientar o que entendemos por ser uma boa educação. $\mathrm{E}$ ao não discutir, impõe aquela que emerge juntamente com os números (FREITAS, 2018, p. 61).

Essa "eficiência" do setor privado para mensurar os resultados das políticas públicas e agirem na proposição de programas, projetos e formações deve ser analisado com cautela e desconfiança. Como o próprio autor alerta, discutem-se os números, não se fala no que os causaram, agindo num discurso de depreciação da escola pública.

A pesquisa de mestrado que originou esse artigo, evidenciou por meio dos dados coletados que a DIS existe dentro de uma estrutura escolar excludente em que as condições materiais não são as mesmas para todos os estudantes, o sistema homogeneíza o que deve ser aprendido e ignora a multiplicidade de fatores que faz com que um aluno possa ou não aprender (SANTOS, 2019). Neste sentido, Carlo (2010) argumenta que mais da metade das variáveis que afetam o rendimento do aluno está fora da escola, ou seja, atribuir apenas à escola a compensação as desigualdades sociais é uma contradição neoliberal e não justifica a ênfase que dão na gestão e gerenciamento senão para seus próprios interesses privados.

Assim, escondidos nos dados das pesquisas, sobretudo de organismos internacionais, como é o Programa Internacional de Avaliação de Alunos (PISA), as reformas educacionais são criadas, sempre justificadas por uma "melhoria da qualidade da educação" e, na verdade, possibilitam o privado a ganhar espaço na educação pública, a exemplo da reforma do currículo escolar que ocorreu recentemente com a Base Nacional Comum Curricular. Freitas discute que a

Base Nacional Curricular Comum, testes de responsabilização e outros dispositivos da reforma são mecanismos implantados de cima para baixo e ancorados em leis que, na prática, levam as redes públicas a recorrer a uma série de possibilidades de privatização por dentro do sistema público (Ball; Youdell, 2007; Adrião, et al. 2016), que conduzirão, em algum tempo, a própria retirada da escola do âmbito do setor público, reinserindo-a em um mercado educacional pleno (FREITAS, 2018, p. 79-80).

\footnotetext{
${ }^{5}$ Mais sobre essa discussão em Freitas (2018); Santos (2013).
} 
Essas iniciativas analisam os problemas da repetência, evasão e abandono através de uma ótica de mercado, com projetos prontos e que em nada criticam as bases do sistema capitalista, que é o responsável pelo desmanche da educação pública. Eles se fundamentam numa visão de que é preciso motivar o aluno, responsabilizando-o pelo seu sucesso ou fracasso; criam iniciativas - projetos e buscam associações com os estados e municípios, e suas influências perpassam também as políticas públicas e as formas com as quais as unidades federativas buscam alcançar as metas estabelecidas. Souza e Moreira (2020, p.421) discutem que

\begin{abstract}
Grupos educacionais privados miram a educação básica como um mercado profícuo para suas ações de vendas de apostilas, livros, formação de professores, gestores, softwares, projetos, consultorias, assessorias, entre outros (ADRIÃO ET AL, 2015; ADRIÃO, 2016; ADRIÃO 2017). Percebe-se que o Estado nesse cenário atua como instituição responsável por favorecer incentivo ao processo de acumulação capitalista e à regulação dos mecanismos legais, associando-se de forma estreita com a privatização da educação.
\end{abstract}

O problema da Distorção Idade-Série não é recente, tampouco as formas de tentar amenizá-la. Mainardes (2009) aponta que esse já era fator de preocupação desde o início do século XX, quando as primeiras atitudes para a diminuição dos índices de reprovação foram tomadas, tais como a promoção automática de alunos e as experiências de escolarização por Ciclo. Tais alternativas consistem nas atitudes defendidas e implementadas durante quase todo o século XX, mas que não lograram êxito, nem tiveram um caráter legal estabelecido pela legislação educacional do país, não consistindo, assim, em política pública. Tendo apenas em 1996, com a LDB número 9.394/96, sido contemplada legalmente.

Bittar e Bittar (2012) ressaltam que os interesses pela organização e implantação de um sistema público educacional no começo do século XX, sobretudo a partir de 1930, era condição essencial para o desenvolvimento socioeconômico do país. Destarte, o cenário educacional no período que compreende 1930-1971 é descrito por Gil (2018, p. 03) da seguinte forma:

\begin{abstract}
Ao examinar as estatísticas escolares entre 1930 e 1971, Romanelli (1978) indicava que a expansão da escola, nesse período, evidenciou uma "oferta insuficiente", um 'baixo rendimento interno' e uma notável 'discriminação social'. Isso decorria da compreensão de que a ampliação das matrículas foi significativa nessas décadas, mas não chegava a oferecer vagas a todas as crianças em idade de frequentar a escola; dos alunos matriculados na $1^{\mathrm{a}}$ série do ensino primário, poucos chegavam às séries seguintes, abandonando a instituição ao longo do percurso; e a reprovação e o abandono dos estudos eram mais acentuados entre os alunos oriundos das camadas populares.
\end{abstract}

Segundo Patto (2015), os alarmantes índices de reprovação no país não eram discutidos no seu viés social, ainda que esses fatores estivessem completamente associados às questões de pobreza, e em sua tese de doutorado, que resultou no livro A produção do fracasso escolar, a autora comprova que o insucesso das crianças pobres se dava pela seletividade interna educacional e não pelas deficiências cognitivas dos educandos. 
A Lei de Diretrizes e Bases 9.394/96 abre o caminho para modificações na questão da organização do ensino, dos tempos de aprendizagem e em formas de enfrentamento para as questões relacionadas à Distorção Idade-Série. O artigo 23, a referida LDB regulariza a organização por Ciclo entre outras formas, inclusive a formação de grupos não-seriados, com base na idade:

Art. 23 A educação básica poderá organizar-se em séries anuais, períodos semestrais, ciclos, alternância regular de períodos de estudos, grupos não-seriados, com base na idade, na competência e em outros critérios, ou por forma diversa de organização, sempre que o interesse do processo de aprendizagem assim o recomendar (BRASIL, 1996).

Assim, abre-se caminho legal para a implantação de turmas de aceleração e de turmas de Ciclo de Aprendizagem com progressão continuada, adotadas, sobretudo, nos últimos anos do século XX. Destaca-se na produção dos materiais, a divulgação e a instalação de turmas de aceleração, o Instituto Ayrton Senna com os programas de regularização de fluxo, através de convênios com governos, estabelecendo as parcerias público-privadas. Neste sentido, é importante destacar o crescimento do setor privado na Educação pública, principalmente através dessas turmas.

Conforme já analisamos em um trabalho anterior (SANTOS; SANTOS, 2018), as pesquisas educacionais, dissertações e teses que têm como objeto a DIS, vêm, em sua maioria, discutindo a eficiência dos programas de aceleração e, sobretudo, o caráter mercadológico embutido em um problema tão sério e complexo, como é a condição dos alunos em distorção. Para abordar a visão mercadológica, destacamos um excerto retirado de um site relacionado ao Instituto Ayrton Senna - Rede Vencer (s/d), que diz:

[...] Para as redes de ensino, a reprovação significa gastos com salas de aulas adicionais e contratos de professores, ou seja, impactos financeiros que poderiam ser usados em outras ações para melhorar a educação.

[...] Nossa proposta é que, em um prazo de quatro anos, as redes de ensino possam diminuir a Distorção Idade-Série no Ensino Fundamental, corrigindo o fluxo escolar e evitando que outras crianças entrem para as estatísticas de analfabetismo, reprovação e abandono. À vista disso, os gestores contam com soluções específicas, desenvolvidas pelo Instituto Ayrton Senna, para montar uma estratégia de atuação e estabelecer metas de desempenho concretas com vistas ao aprendizado do aluno. Esse modelo prevê ações sistematizadas de formação, apoio e orientações a gestores, a coordenadores escolares e a professores (REDE VENCER, [s.d.], grifos nossos).

A preocupação acentua-se nos gastos com as salas de aula que possuem alunos repetentes. Assim, a criação e a divulgação de seus materiais prontos oferecem uma alternativa que promete solucionar o problema em poucos anos, livrando os municípios desse "gasto", ou seja, a educação torna-se um negócio, não figura mais no campo do direito, e, novamente, busca atacar as consequências, não a causa, a raiz do problema. Parente e Lück tratam da questão da descontinuidade e da avaliação nesses programas de aceleração da aprendizagem: 
[...] em geral, não se monitoram os processos nem se avaliam os resultados dos programas, em vista de que são tomadas decisões a respeito de continuidade, descontinuidade ou alteração de programas, tendo por base muito mais observações isoladas e opiniões do que informações globais objetivamente coletadas e devidamente analisadas e interpretadas. Sem tal prática, não é possível melhorar o trabalho nem reconhecer se o que vem sendo feito no plano educacional produz resultados compatíveis com o dispêndio realizado (PARENTE; LÜCK, 2007, p. 18).

Seguindo os pressupostos neoliberais, a década de 1990 marca o início de uma acentuada ênfase nas avaliações. De acordo com Afonso (2000, p.49), esse interesse

[...] parte de governos neoconservadores e neoliberais, começou a ser traduzido pela expressão 'Estado avaliador' (cf. Neave, 1988; Henkel, 1991b; O’Buachalla, 1992; Hartley, 1993). Esta expressão quer significar em sentido amplo, que o Estado vem adotando um ethos competitivo, neodarwinista, passando a admitir a lógica do mercado, através da importação para o domínio público de modelos de gestão privada, com ênfase nos resultados ou produtos do sistema educativos (AFONSO, 2000, p. 49, grifos do autor).

Nisso, o autor critica essa nova concepção, pois o mesmo retoma o viés positivista na educação, indicando que a ênfase nos indicadores pode resultar em mudanças nas práticas avaliativas apenas para alcançar as metas estabelecidas. Assim, "a preocupação com o produto, mais do que com o processo, é uma das tônicas da avaliação no contexto do Estado Avaliador" (AFONSO, 2000, p. 50). Essa ênfase pelos resultados que possam atender as metas estabelecidas e as consequentes cobranças pelas quais passam os entes federados (estados e municípios) faz com que as políticas sejam voltadas aos resultados, sem uma reflexão no processo e na problematização das raízes do problema.

Pode-se notar que esse Estado Avaliador atua com bastante força, principalmente, nas primeiras décadas do século XXI. Desde a criação do Sistema de Avaliação da Educação Básica (SAEB), em 1990, ela veio se aperfeiçoando na reformulação das avaliações em larga escala e em 2005, foi criada a Avaliação Nacional do Rendimento Escolar (Anresc), conhecida como Prova Brasil, com o objetivo de avaliar a qualidade do ensino ministrado nas escolas das redes públicas.

Em 2007, com o decreto $\mathrm{n}^{\circ}$ 6.094, que dispõe sobre a implementação do Plano de Metas Compromisso Todos pela Educação, cria-se o Índice de Desenvolvimento da Educação Básica, o IDEB, indicador para a verificação do cumprimento de metas fixadas no Termo de Adesão ao Compromisso "Todos pela Educação". O IDEB reúne, em um só indicador, os resultados de dois conceitos igualmente importantes para a qualidade da educação: o fluxo escolar e as médias de desempenho nas avaliações (INEP, $[s . d]$ ).

O interesse pelo crescimento do IDEB objetiva colocar o país nos níveis de qualidade mensurados pela Organização para Cooperação e Desenvolvimento econômico (OCDE), que, para 2021, é de 6,0. A relação intrínseca entre o alcance dos índices e o cumprimento do compromisso Todos pela Educação, fez com que o governo criasse o Plano de Desenvolvimento da Educação (PDE) e o Plano de Ações Articuladas que atua no acompanhamento das ações de cada município e através do qual é feito o repasse de verbas para implantação de programas educacionais.

Como o IDEB associou o desempenho do ensino (proficiência em Língua Portuguesa e Matemática) às taxas de aprovação/reprovação, ou seja, colocou em evidência dois 
problemas educacionais agudos, explicitando a necessidade de ações políticas para a resolução desses, que são problemas impeditivos ao crescimento da posição do Brasil no acompanhamento feito pela OCDE, cresce o interesse pelo desenvolvimento de políticas de avaliação e, por conseguinte, programas para amenizar as disparidades de fluxo escolar.

Atrelar a qualidade da educação a metas específicas e condicionar o repasse de recursos às melhorias nesses índices coloca os municípios numa competição. Essa forma de gestão faz com que ações praticadas não reflitam a problemática real por trás dos problemas de ensino e responsabiliza os sujeitos por aquilo que deveria ser dever do Estado.

A respeito do caráter neoliberal dessa forma de gerir a educação, Araújo diz que

O IDEB é mais um instrumento regulatório do que um definidor de critérios para uma melhor aplicação dos recursos da União visando alterar indicadores educacionais. O resultado de cada município e de cada estado será (e já está sendo) utilizado para ranquear as redes de ensino, para acirrar a competição e para pressionar, via opinião pública, o alcance de melhores resultados (ARAÚJO, 2007, p. 04).

Além do caráter competitivo, Afonso (2000) destaca a autonomia do professor na ótica do Estado Avaliador, em que ele se sente apenas um executor de políticas as quais não participou da elaboração. Segundo Afonso,

M. Apple e S. Jungck comentaram que, muito embora se visse explicitamente garantir algum tipo de controlo de qualidade, um dos principais efeitos dessa intervenção do Estado tem sido uma considerável pressão sobre os professores para ensinar meramente para testes (cf. Apple; Jungck, 1992, p.23). Também, sobre este mesmo tema, Carlos Rosales afirma: "É evidente que este processo de avaliação externa dá lugar a uma notável desprofissionalização da função docente. O professor de algum modo, deixa de ser dono dos seus próprios actos, perde autonomia profissional e converte-se num instrumento de objetivos e de normas impostas de fora para dentro" (AFONSO, 2000, p. 40, grifos do autor).

Desde 2007, atuando junto às políticas de avaliação, buscando apoiá-las no cumprimento dos objetivos, o Plano de Ações Articuladas (PAR) assegura o acompanhamento dos municípios para que possam melhorar os índices na avaliação externa. A Distorção Idade-Série perpassa pelas ações necessárias. Segundo Santos, Cardoso e Oliveira (2018) o PAR surge num contexto de Nova Gestão Pública, atrelado aos interesses dos Organismos internacionais como Banco Mundial e a OCDE que busca aproximar as formas de produção do setor público com o setor privado. ${ }^{6}$

No documento, ela aparece, especificamente na dimensão três, Práticas Pedagógicas e Avaliação, cujas áreas são: 1. Elaboração e Organização das práticas pedagógicas; 2. Avaliação da aprendizagem dos alunos e tempo para assistência individual/coletiva aos alunos que apresentam dificuldade de aprendizagem. As ações estão voltadas para incentivos à criação de programas de fluxo, acompanhamento dos alunos que possuem dificuldades, reuniões para planejamento de práticas e metodologias de ensino, registros de frequência e encaminhamento dos alunos que não frequentam aos órgãos responsáveis, diversidade de

\footnotetext{
${ }^{6}$ Mais sobre o PAR e a sua relação com o empresariamento da educação em Oliveira (2016).
} 
instrumentos avaliativos, programas de incentivo à leitura (MEC, 2011). Além dos programas como Novo Mais Educação, Mais Alfabetização, Pacto Nacional pela Alfabetização na Idade Certa que surgiram e foram se reformulando desde a criação do PDE.

Apresentamos, por fim, no quadro 3, a evolução nos índices de DIS no Brasil, para o período entre 2008 e 2018 em cada etapa da Educação Básica:

\begin{tabular}{|l|l|l|}
\hline \multicolumn{1}{c|}{} & Quadro 3 - DIS nas escolas públicas 2008-2018 \\
\cline { 2 - 3 } & \multicolumn{2}{c|}{ Escolas Públicas } \\
\cline { 2 - 3 } & $\mathbf{2 0 0 8}$ & $\mathbf{2 0 1 8}$ \\
\hline Anos Iniciais & $25 \%$ & $14 \%$ \\
\hline Anos Finais & $37 \%$ & $29 \%$ \\
\hline Ensino Médio & $47 \%$ & $31 \%$ \\
\hline
\end{tabular}

Fonte: Censo escolar (2018). Elaboração própria,

Analisando o quadro 3, é perceptível que os índices diminuíram significativamente em 10 anos, apesar de que ainda segues altos, principalmente nas etapas finais do ensino básico. Importante também reiterar que esse é um quadro geral que não mostra as desigualdades e disparidades entre regiões, estados e municípios. Na dissertação, a pesquisa mostrou que a diminuição dos índices não estava atrelada diretamente à uma ação específica de nenhum programa, nem vinha de um processo de transformação na política educacional do município analisado, mas de uma aspiração e direcionamento da gestão municipal em melhorar os indicadores do IDEB do município. Entretanto, não podemos fazer essa análise em termos de país, nem é o objetivo deste texto. Nos propusemos a analisar os índices e problematizar os seus resultados, e estes sugestionam a necessidade de uma ação que enfrente a raiz do $\begin{array}{lllll}\text { problema } & \mathrm{em} & \text { todos segmentos. }\end{array}$

\section{CONSIDERAÇÕES FINAIS}

Neste texto buscamos abordar as causas da DIS, e como estas estão relacionadas a uma proposta de governo que se sucumbe aos interesses dos organismos internacionais e do setor empresarial na educação do Brasil. Também buscamos demonstrar a forma como o Estado neoconservador condiciona a criação de políticas e programas educacionais no sentido de cumprir as metas estabelecidas para a sua manutenção e legitimação. Isso impacta no currículo, na avaliação e na forma como é desenvolvido o trabalho do professor.

A preocupação exacerbada com os exames internacionais faz parte do processo de esvaziamento dos conhecimentos historicamente construídos e concebidos como importantes para a apropriação e emancipação da classe trabalhadora. Porém, para que aconteça a aprendizagem com qualidade faz-se necessário que as escolas tenham boas estruturas físicas, e que os professores tenham a formação inicial e continuada adequada. A falta destes elementos contribui para a reprovação/evasão, e também para que não se avance uma avaliação emancipatória, ao contrário, o que acontece é que por meio do caráter disciplinador e conservador as avaliações têm sido utilizadas de modo autoritário impregnando a cultura do medo da reprovação e da exclusão, que por sua vez, tem como consequência, a DIS. Os fatores econômicos e sociais também não podem ser ignorados, e nesse sentido, os dados de nossa pesquisa apontaram que as 
variáveis externas à escola também impactam diretamente no rendimento escolar, quais sejam: questões culturais, econômicas e estruturais.

No que ser refere à política educacional, evidenciamos a necessidade de uma postura para além da aparência do fenômeno, de modo que a DIS seja compreendida em suas múltiplas determinações, cuja essência se encontra na forma como se sustenta o próprio sistema capitalista neoconservador. Portanto, acreditamos que devemos seguir uma postura anticapitalista, buscando espaço para o enfrentamento e a negação da destruição da educação pública, o que se torna essencial para vencermos a batalha contra a desigualdade social e educacional.

\section{REFERÊNCIAS}

ABBAGnANO, N. Dicionário de Filosofia. São Paulo: Martins Fontes, 1997.

AFONSO, A. J. Avaliação educacional: regulação e emancipação: para uma sociologia das políticas avaliativas contemporâneas. São Paulo: Cortez, 2000.

ALVES, J. S; MELO JÚNIOR, A. L. de; CAIADO, K. R. M. Um olhar sobre as políticas públicas da Educação do Campo e Educação Especial à luz da Pedagogia Histórico-Crítica. Revista Educação e Fronteiras On-Line, Dourados/MS, v.8, n.23 p.192-209, maio/ago. 2018.

ARAÚJO, L. Os fios condutores do PDE são antigos. Jornal de Políticas Educacionais, n. 2, set. 2007, p. 24-31.

BITTAR, M; BITTAR, M. História da Educação no Brasil: a escola pública no processo de democratização da sociedade. Acta Scientiarum. Education Maringá, v. 34, n. 2, p. 157-168, jul./dez. 2012.

BRASIL. Constituição da República Federativa do Brasil: promulgada em 5 de outubro de 1988.

BRASIL. Decreto 6.094, de 24 de abril de 2007. Dispõe sobre a implementação do Plano de Metas Compromisso Todos pela Educação, pela União Federal, em regime de colaboração com Municípios, Distrito Federal e Estados, e a participação das famílias e da comunidade, mediante programas e ações de assistência técnica e financeira, visando a mobilização social pela melhoria da qualidade da educação básica. Disponível em: http://www.planalto.gov.br/ccivil_03/_ato2007-2010/2007/decreto/d6094.htm. Acesso em: 24 out. 2018. 
BRASIL. Lei $n$. 9.394, de 20 de dezembro de 1996. Estabelece as diretrizes e bases da educação nacional. Diário Oficial [da] República Federativa do Brasil, Poder Legislativo, Brasília, DF, 23 dez. 1996.

CARLO, M. D. Teachers Matter, But So Do Words. 14 de Julho de 2010. Disponível em http://www.shankerinstitute.org/blog/teachers-matter-so-do-words. Acesso em 25 de abr de 2019.

FREITAS, L. C. de. A reforma empresarial da educação: nova direita, velhas ideias. 1 ed. São Paulo: Expressão Popular, 2018.

FREITAS, L. C. de. Crítica da organização do trabalho pedagógico e da didática. Campinas: Papirus, 1995.

FREITAS, L. C. de. Os reformadores empresariais da educação e a disputa pelo controle do processo pedagógico na escola. Educ. Soc., Campinas, v. 35, nº. 129, p. 1085-1114, out.-dez., 2014.

Fundação Lemann e Meritt (2012): portal QEdu.org.br. Acesso em 18 de set. 2019.

GIL, N. de L. Reprovação escolar no Brasil: história da configuração de um problema político-educacional. Revista Brasileira de Educação, Rio de Janeiro, v. 23. 2018.

GROPPO, L. A. Das origens ao colapso do estado de bem-estar: uma recapitulação desmistificadora. Revista HISTEDBR On-line, Campinas, n.20, p. 68 - 75, dez. 2005 ISSN: 1676-2584.

KOSIK, K. Dialética do concreto. Rio de Janeiro: Paz e Terra, 1976.

LIMA, I. G. de; HYPOLITO, A. M. A expansão do neoconservadorismo na educação brasileira. Educ. Pesqui., São Paulo, v. 45, e190901, 2019.

MAINARDES, J. A escola em ciclos: fundamentos e debates. São Paulo: Cortez, 2009.

MANDELERT, D. Reprovação em escolas de prestígio. Est. Aval. Educ., São Paulo, v. 23, n. 53, p. 222-249, set./dez. 2012.

MARSIGLIA, A. C. G; PINA, L. D; MACHADO, V. de O. M; LIMA, M. A Base Nacional Comum Curricular: um novo episódio de esvaziamento da escola no Brasil. 
Germinal: Marxismo e Educação em Debate, Salvador, v. 9, n. 1, p. 107-121, abr. 2017. ISSN: $2175-5604$.

MARX, K. O Capital: crítica da economia política, livro I. - 33 ed. - Rio de Janeiro: Civilização Brasileira, 2014.

MÉSZÁROS, I. A crise estrutural do capital. 2. ed. São Paulo: Boitempo, 2011.

OLIVEIRA, B. A. de. O Plano de Ações Articuladas - PAR: o processo de indução das Políticas Educacionais dos sistemas municipais de ensino. 2016. Tese (Doutorado em Educação) - Centro de Educação e Ciências Humanas, Universidade Federal de São Carlos, São Carlos, 2016.

PARENTE, M. M. A; LÜCK, H. Aceleração da aprendizagem para corrigir o fluxo escolar: o caso do Paraná. Brasília: IPEA, 2007.

PATTO, M. H. S. A produção do fracasso escolar: histórias de submissão e rebeldia. São Paulo: Intermeios, 2015.

REDE VENCER. Políticas de aprendizagem escolar. [S.d]. Disponível em: $<$ http://www.redevencer.org.br/sme/conteudoinstitucional/menuesquerdo/SandBoxIt emMenuPaginaConteudo.ew?idPaginaItemMenuConteudo=7349>. Acesso em: 26 nov. 2018.

SANTOS, V. P. dos. A Distorção Idade-Série nas escolas do campo: um estudo sobre os anos iniciais do ensino fundamental em Nazaré-Ba. Dissertação de Mestrado. IlhéusBa, UESC, 2019. 217 F.

SANTOS, Valéria Prazeres dos; SANTOS, Arlete Ramos dos . DISTORÇÃO IDADESÉRIE: estado do conhecimento. In: XXIV Encontro de Pesquisa Educacional do Nordeste, 2018, João Pessoa. Anais das Reuniões Regionais da ANPEd, 2018.

SOUZA, T. G. de; MOREIRA, J. A. da. S. Políticas de privatização na educação pública e a atuação de grupos educacionais privados. Revista Práxis Educacional, Vitória da Conquista-Bahia-Brasil, v. 16, n. 39, p. 421-449, abr./jun. 2020.

Recebido:05/05/2020

Aprovado: 09/07/2020 